\title{
O PROBLEMA DA OBJETIVIDADE E DA SUBJETIVIDADE NAS TEORIAS SOCIAIS CLÁSSICAS E CONTEMPORÂNEAS: um debate necessário'
}

"Um dos principais obstáculos para uma sociologia científica é o uso que fazemos de oposições comuns, pares de conceitos, ou o que bachelard chama "pares epistemológicos": construídos pela realidade social, eles são impensadamente usados para construir a realidade social. Uma dessas antinomias fundamentais é a oposição entre objetivismo e subjetivismo." ( $P$. Bourdieu)

Ileizi Luciana Fiorelli Silva

Prof $^{a}$ do Departamento de Ciências Sociais da Universidade Estadual de Londrina

Este artigo pretende discutir o problema da objetividade e subjetividade a partir dos teóricos clássicos Marx, Durkheim, Weber e do teórico contemporâneo P. Bourdieu, indicando pontos de divergência e convergência compreendidos no interior do conteúdo conceitual de cada referencial teórico específico, bem como, as contribuições de cada um ao debate "objetivismo e subjetivismo"

Palavras-Chave: Objetividade; Subjetividade; Teoria Sociológica

A $\mathrm{s}$ teorias sociológicas clássicas, diante da necessidade de estabelecer métodos de pesquisa e de adquirir status de cientificidade, procuram discutir a questão da objetividade e da subjetividade, buscando sempre mostrar a objetivação, da relação sociedadeindivíduo, amparada em causalidades e finalidades ontológico-sociais. Nesta discussão as teorias de Durkheim, Marx e Weber possuem pontos de convergência e divergência que devem ser compreendidos no interior de cada teoria, para não perderem o conteúdo conceitual específico, que ainda permanece no debate atual entre as teorias sociais contemporâneas.

Refletir sobre este problema é uma tarefa sempre presente na ciências sociais, e por isso, pretendo neste trabalho retomar a questão objetivismo-subjetivismo a partir das teorias sociais clássicas e contemporâneas, procurando apreender o desenvolvimento deste debate e sob quais termos está colocado na atualidade.

Ao analisarmos a questão objetivismosubjetivismo, pensamos simultaneamente a relação indivíduo-sociedade, pois, é a partir desta relação

\footnotetext{
${ }^{1}$ Este artigo é fruto de reflexões realizadas nas aulas da disciplina "Teoria Social I" do Curso de Especialização em Sociologia e Sociologia da Educação, UEL, ministrada pelas professoras Ana M. C. de Almeida e Maria Helena Antuniassi, no primeiro semestre de 1995
} 
que os pensadores clássicos e contemporâneos constróem suas concepções sobre esta questão.

Durkheim procurou esclarecer minuciosamente a forma desta relação fundamental, mostrando o quanto o indivíduo é subjugado à sociedade. Para Durkheim a sociedade em suas expressões concretas, como a consciência coletiva e o fato social, é obra dos indivíduos, e disso decorre seu caráter subjetivo, porém ela se torna exterior ao indivíduo, impondo-se a ele imperiosamente, revelando o seu caráter objetivo. $\mathrm{O}$ cientista social deverá procurar nas regras sociais, nos valores e na moral o conteúdo "espiritual" da sociedade objetivado na realidade. Desta premissa decorre o objetivismo de Durkheim, que coloca a sociedade como coisa imanente à vontade individual, vontade esta que deverá ser moldada no processo de socialização através da educação. Assim, a sociedade modifica a natureza psíquica do indivíduo, elevando-o acima de sua natureza física (análoga a dos outros animais). (Durkheim, 1983)

Neste processo de socialização os grupos sociais dispõem de coerção para impor as maneiras de pensar e agir, e impedir as dissidências, imputando um caráter despótico à sociedade, que é natural e absolutamente suportável para o indivíduo, conforme afirma Durkheim:

\section{"(...) o individuo não o sente, tal como não sentimos a atmosfera que nos pesa sobre os ombros. Desde que o individuo foi criado, educado pela coletividade, dessa forma, quer naturalmente aquilo que ela quer, e aceita sem dificuldade o estado de sujeição ao qual está reduzido." (Durkheim, 1983: 56)}

A sujeição do indivíduo à sociedade é algo natural e aceitável, faz parte da natureza humana criar o mundo social, com regras e sentimentos morais para garantir a coesão entre os indivíduos, e, para que tais regras morais sobrevivam, necessitam tornar-se maior que seus criadores (maior que os indivíduos).

Para Durkheim o aspecto subjetivo da sociedade se manifesta nas seguintes premissas:

a) os indivíduos criam coletivamente a sociedade, com regras que se colocam acima de todos para garantir a coesão do tecido social;

b) os indivíduos internalizam essas regras morais através da educação e da coerção e passam a desejá-las, almejando apenas o que é consenso na sociedade, ou seja, sendo o homem que condiz com os interesses da sociedade de sua época.
São estas premissas que permitem pensar a sociedade objetivamente, pois, a subjetividade é social, e para apreendê-la basta compreendermos como as sociedades se objetivam através de suas instituições, regras, controles, enfim, de sua consciência coletiva.

O estudo de Durkheim sobre as formas primitivas de classificação ilustram bem a sua concepção sobre as categorias do pensamento humano. Nestes estudos procurou demonstrar o quanto os sistemas de classificação constituem representações coletivas, cuja as divisões internas remetem às divisões morfológicas da organização social, ou seja, a organização interna dos sistemas de classificação obedece a um modelo fornecido pela sociedade. (Miceli, 1982: 20) A partir disto, Durkheim julga resolver o problema de como o homem pensa e cria símbolos, pois, a fonte do pensamento é da simbologia é a sociedade.

Certamente que a conclusão de Durkheim não resolveu o problema epistemológico que envolve a objetividade e a subjetividade, e, teorias contemporâneas, como o estruturalismo de LéviStrauss ${ }^{1}$ retoma esta questão a partir dos pressupostos de Durkheim e Mauss, porém invertendo os termos do problema. Se para Durkheim a vida psíquica individual tem sua fonte na organização social, para Lévi-Strauss os símbolos, os sistemas classificatórios e as organizações sociais se originam a partir da vida psíquica, ou seja, da forma constante nos indivíduos de explicar e fazer o mundo social.

Como explica Miceli:

"Segundo L. Strauss, o psíquico é ao mesmo tempo elemento de significação para um simbolismo que o ultrapassa e único meio de verificação de uma realidade cujos múltiplos aspectos só podem ser captados sob forma de sintese fora dele. O caráter singular do fato social que o torna simultaneamente coisa $e$ representação compele o cientista a passar de uma apreensão externa, objetiva, a uma apreensão subjetiva através da qual incorpora-se a mesma realidade do ânoulo $m$ que se encontra o agente individual capaz de vivê-la em seu cotidiano."(Miceli, 1982: 23)

\footnotetext{
${ }^{1}$ Não aprofundaremos os conceitos da teoria de Lévi-Strauss, por não ser o objetivo específico deste trabalho. Pode-se ver a respeito Lévi-Strauss, Claude. Antropologia Estrutural. Rio de Janeiro: Tempo Brasileiro, 1985.
} 
Esta perspectiva de análise procura apreender o objetivo pelo subjetivo, entretanto, despe o subjetivo (a elaboração de símbolos) do seu caráter histórico, dando-lhe um caráter sincrônico e uma forma quase universal. Passando de um objetivismo a um subjetivismo. ${ }^{2}$

A teoria de Marx (e a maior parte da tradição marxista) confere um tratamento diferente a esta problemática. Marx (1977) procura apreender a objetividade e a subjetividade diacronicamente, conforme indicam seus pressupostos sobre a história social.

Marx procurou apreender o movimento histórico-social a partir da concepção materialistadialética sobre a relação homem-natureza, pois, é nesta relação que aparece a essência humana criadora e generalizadora, enquanto subjetividade expressada através do trabalho, meio pelo qual esta essência humana se objetiva.

A partir deste pressuposto, torna-se importante para Marx compreender as formas dominantes de trabalho nas sociedades em geral e em particular na sociedade capitalista, uma vez que é no modo de organizar a produção que se encontram as formas e os conteúdos das relações sociais estabelecidas entre os indivíduos. Neste sentido, Marx considera que o homem é o principal sujeito histórico criador das diferentes formações sociais, contudo, ele faz a história não como deseja, mas sim a partir de circunstâncias determinadas objetiva e subjetivamente (MARX, 1973).

Isto indica que para Marx o indivíduo é subjugado à fatores externos a ele, à sua vontade, ou seja, as formações sociais engendram mecanismos de autoreprodução que escapam ao controle individual, e neste ponto seu pensamento se aproxima do pensamento de Durkheim. Entretanto, se distancia, na medida em que para Marx o problema do indivíduo estar subjugado à sociedade é um problema de alienação, que se intensificou e se sofisticou muitíssimo na sociedade capitalista.

A alienação do ser trabalhador ocorre no processo de produção capitalista, quando o indivíduo perde seus meios de produção, que passam a ser propriedade privada de poucos. Diante disto, os indivíduos que alienaram seus meios de produção, passam a alienar sua força de

\footnotetext{
${ }^{2}$ Esta tendência de privilegiar ora o subjetivo, ora o objetivo, como conceitos opostos será criticada por Bourdieu, que apresenta uma proposta de superação, que será apresentada
} posteriormente neste trabalho. trabalho bem como o seu produto final. Vendem sua força de trabalho para os proprietários dos meios de produção, dentro de uma organização produtiva baseada na divisão do trabalho, alienando-se, também, do controle da produção como um todo, uma vez que só realiza uma parte de um conjunto de tarefas necessárias à produção de um único produto.

Para Marx este processo de produção nega o homem em sua essência, pois, toda sua criatividade torna-se externa a ele, não se identificando com os objetos que produziu, estes objetos (mercadorias) ${ }^{3}$ ganham vida própria, independentes dos indivíduos, fazendo com que a alienação não seja apenas material, mas, sobretudo, uma alienação da subjetividade do sujeito.

Segundo Marx esta alienação é superável na medida em que o sistema capitalista seja superado, contudo esta superação não depende somente da vontade dos indivíduos e sim de forças sócioeconômicas-políticas-ideológicas externas a ele, que obedecem o ritmo de desenvolvimento calcado em leis contraditórias.

Explicando com as palavras de Marx:

"E do mesmo modo que não podemos julgar um
indivíduo pelo que ele pensa de si mesmo, não podemos
tampouco julgar estas épocas de revolução pela sua
consciência, mas, pelo contrário, é necessário explicar
esta consciência pelas contradiçôes da vida material,
pelo conflito existente entre forças produtivas sociais e
as relaçôes de produção. Nenhuma formação social
desaparece antes que se desenvolvam todas as forças
produtivas que ela contém e jamais aparecem relaçôes
de produção novas e mais altas antes de amadurecerem
no seio da própria sociedade antiga as condiçôes
materiais para a sua existência. Por isso, a
bumanidade se propõe sempre apenas os objetivos que
pode alcançar."(Mara, 1973: 30-32)

Assim, para que o homem recupere sua essência criadora e generalizante, precisam amadurecer as condições objetivas (as contradições entre as forças produtivas sociais e as relações de

\footnotetext{
${ }^{3}$ A teoria de Marx sobre mercadoria e valor é extremamente interessante, uma vez que analisa a mercadoria e o valor em seus conteúdos objetivos e subjetivos. Ver a respeito GERAS, N. "Essência e aparência: aspectos da análise da mercadoria em Marx" IN: Cohn, G. (org.) Sociologia: para ler os clássicos. Rio de Janeiro, 1977
} 
produção) e as condições subjetivas (a consciência do homem sobre os conflitos e contradições) ${ }^{4}$.

Percebe-se que a teoria de Marx pretende apreender os fenômenos sociais em sua totalidade, partindo do aspecto produtivo do homem, e para tanto cria conceitos genéricos e abrangentes, que mesmo procurando dar conta dos aspectos objetivos e subjetivos tende a acentuar o caráter objetivo da relação indivíduo e sociedade.

Esta tendência tem sido alvo de críticos, e o próprio Max Weber iniciou este debate, quando apontou a ênfase que Marx deu aos aspectos produtivos como um limite metodológico.

Para Weber o estudo sobre quaisquer fenômenos sociais não possui a priori um ponto de partida fixo. Entretanto, vê como ponto fundamental a ação do indivíduo, a motivação causal das ações individuais que compõem a sociedade. Por isso, refuta a idéia de que exista algum aspecto (econômico, social, político, ideológico) mais fundamental que outro.

Ao dar relevância para o conjunto de valores, de motivos que impulsionam as ações individuais e sociais, Weber coloca a questão da subjetividade como força fundamental nos fenômenos sociais. Por isso, procurou encontrar em seus estudos econômicos o significado cultural, ou seja, os significados que os indivíduos atribuíram a determinados aspectos econômicos da vida social.

Deste pressuposto decorre a reflexão que Weber faz acerca de conceitos generalizantes nas ciências humanas, que são condicionados pelo conteúdo da cultura da época em que foram elaborados, e por isso, os conceitos revelam tanto um problema teórico carregado de conteúdo cultural significativo, quanto um problema empírico. Desta forma, o pesquisador social necessita esclarecer ao máximo os conceitos utilizados, que serão, diferenciados de acordo com o fenômeno estudado. ${ }^{5}$

As reflexões de Weber acerca do objetivo e subjetivo colocam a possibilidade de síntese entre estes aspectos. Mesmo guardando certa ressonância

\footnotetext{
${ }^{4}$ são elementos importantes dentro da discussão sobre classes e consciência de classe em Marx, ver a respeito RIDENTI, Marcelo. Classes Sociais e representação. São Paulo: Cortez, 1994.

${ }^{5}$ Weber cria os tipos ideais como um referêncial teóricoconceitual válido para cada conjunto de fenômenos em seus contextos específicos, ver a respeito FREUND, J. A sociologia de Marx Weber. Rio de Janeiro: Forense, 1970.
}

com o racionalismo objetivista de Kant, Weber consegue perceber a importância do caráter subjetivo nos fenômenos culturais e no próprio cientista.

Uma teoria contemporânea que tenta superar a oposição entre objetividade e subjetividade é a sociologia dos sistemas simbólicos de P. Bourdieu que segundo Miceli (1982) se apresenta como uma depuração criativa das linhas clássicas da sociologia.

Bourdieu procura assimilar das teorias clássicas conhecimentos que julga relevantes para o avanço da sociologia enquanto ciência. Por isso, é acusado, muitas vezes, de ecletismo, quando na verdade ele não pretende a junção das diferentes teorias, mas, sim a valorização do que pode contribuir e a refutação do que é obstáculo para uma sociologia realmente científica.

No caso da teoria de Durkheim, Bourdieu considera importante a ênfase dada à sociedade, enquanto elemento fundante das práticas individuais, entretanto, considera excesso de objetivismo quando aponta as práticas individuais como elementos estruturados, negando seus caráter estruturante e subjetivo.

Para Bourdieu utilizar conceitos generalizantes, como por exemplo, consciência coletiva, leva o cientista a cristalizar as práticas sociais, distanciando-o da realidade concreta.

A mesma reflexão vale para a teoria de Marx, que segundo Bourdieu, tende a buscar uma explicação para o todo através de conceitos muito gerais que não apreendem as práticas sociais em suas experiências específicas.

Essa pretensão de apreender a realidade macrosocial levou a teoria de Marx a caracterizar os aspectos culturais e ideológicos (simbólicos) como mecanismos funcionais de reprodução das relações de produção. Althusser radicalizou esta característica em sua teoria sobre os aparelhos ideológicos de Estado. Partindo da premissa marxiana, porém, modificando-a na medida em que confere total autonomia aos mecanismos ideológicos, despindo-os das ações individuais e das relações de produção circunscritas num contexto histórico específico, "privilegia a realidade do modelo em detrimento do modelo da realidade (nesse ponto ocorre uma coincidência metodológica entre o formalismo althusseriano e a hermenêtica estruturalista)". (Miceli, 1982: 25). 
Essas teorias pensam a práxis social no plano do sistema de relações construídas teoricamente, não apreendendo essas práxis historicamente, não percebem que o processo real pode transformar a lógica provisória com que opera a ciência. Neste sentido, Bourdieu acaba por aderir à sentença de Marx para quem "as coisas da lógica não devem ser tomadas pela lógica das coisas".

Bourdieu defende que uma saída para o objetivismo é analisar os fenômenos sociais a partir da prática dos agentes nos diferentes campos que formam o espaço social. E, neste ponto, se aproxima de Weber, que afirmava a ação individual como sendo fonte de significados e motivações causais inerentes aos fenômenos sociais. Weber também refuta as pretensões teóricas totalizantes e deterministas, que conferem às certas "leis" ou certas "instâncias" o poder explicativo das práticas culturais, premissa assimilada por Bourdieu.

A originalidade de Bourdieu nesta discussão, consiste na elaboração da noção de Habitus, enquanto "conceito capaz de apreender as estruturas cognitivas (estruturas sociais incorporadas) que os agentes sociais colocam em marcha para conhecer praticamente o mundo social." O habitus se constitui em "sistemas de disposições adquiridas, duráveis e transponíveis, estruturas estruturadas predispostas a funcionar como estruturas estruturantes, quer dizer como princípios geradores e organizadores de práticas e representações."

O habitus aponta um princípio gerador de esquemas duráveis, porém, flexíveis, ou seja, que ao mesmo tempo reproduz as regularidades presentes nas condições objetivas e permite inovações de acordo com as exigências postas pelas situações concretas. Desta forma, a mediação operada pelo habitus entre estruturas estruturadas (condições objetivas) e estruturas estruturantes confere um espaço de liberdade à práxis social, ou seja, um espaço de ação do indivíduo com possibilidades de se impor à sociedade.

Para Bourdieu "as práticas sociais são processos dinâmicos, onde a objetividade se enraiza na e pela experiência subjetiva", e, portanto, tendem, ao mesmo tempo, à reprodução e à transformação. Superando assim, a antinomia objetivismo e subjetivismo, uma vez que toda experiência subjetiva revela a objetividade, e toda objetividade revela intenções subjetivas.
A noção de habitus é melhor compreendida enquanto modus operandi nos diferentes campos sociais.

O espaço social é composto por diferentes campos (econômico, simbólico, cultural, social, etc.) onde se definem posições e tomadas de posições dos agentes condicionadas pela quantidade de capital de que dispõem (capital econômico, simbólico, cultural e social). Assim, os agentes sociais interagem nos diferentes campos utilizandose de estratégias que dependem do tipo e da quantidade de capital adquirido durante a constituição do habitus (que se caracteriza a partir da estrutura destes diferentes campos).

Os campos são espaços de relações que devem ser pensados enquanto processos de lutas políticas, onde, os agentes buscam posições mais confortáveis, e, por isso, as mudanças de posições são fatos fundamentais para a análise. A apreensão do "sentido da posição ocupada no espaço social se dá no domínio prático da estrutura social no seu conjunto, o qual se descobre através do sentido da posição ocupada nessa estrutura." (Bourdieu, 1989: 141).

A tarefa do sociológico seria, justamente, apreender estes sentidos das posições dentro dos campos, ou do espaço social. E para conseguir isto, a ruptura com a ciência objetivista, com conceitos generalizantes e com conceitos metafísicos é condição sine qua non.

$\mathrm{O}$ pesquisador deverá construir seu objeto e seus conceitos simultaneamente, para apreender as práticas sociais em sua gênese e em sua especificidade, "conhecendo as categorias que tornam possível o mundo social, pois, são elas que estão em jogo na luta política, luta ao mesmo tempo teórica e prática pelo poder de conservar ou de transformar o mundo social, conservando ou transformando as categorias de percepção desse mundo." (Bourdieu, 1989: 142)

Este pressuposto permite superar por um lado o determinismo (objetivista ou subjetivista), e por outro lado o espontaneismo sociológico. Supera o determinismo porque as práticas sociais não são analisadas a partir de conceitos pré-elaborados (de grandes teorias como o funcionalismo, marxismo, estruturalismo, etc) que colocam de antemão conclusões sobre o que são essas práticas; mas, ao contrário que as práticas sociais, os pontos de vistas e as visões de mundo múltiplas e variadas sejam apreendidas do ponto de vista relacional na 
sua concretude. Portanto, o sociólogo deverá construir seu objeto e seus conceitos. Supera também o espontaneismo no sentido de que quando se fala em descobrir as categorias que os agentes utilizam para representar o mundo corre-se o risco de indicar que os próprios agentes sociais explicam os problemas e as práticas sociais, e o ofício do sociólogo seria o de colocá-los no plano científico. $\mathrm{Na}$ verdade, o sociólogo deve transformar problemas sociais em problemas sociológicos, tais problemas não estão sempre explícitos (não são sempre conscientes) para os agentes sociais. O sociólogo deverá apreendê-los nas práticas reais dos agentes, representando-os através de conceitos específicos que possam explicá-los e sistematizálos. Desta forma,

“(...) constroem-se, pouco a pouco espaços sociais os quais - embora só se ofereçam em forma de relações objetivas muito abstratas e se não possa tocá-los nem apontá-los a dedo são os que constituem toda a realidade do mundo social." (Bourdieu, 1989: 30).

Podemos perceber que as reflexões de Bourdieu indicam algumas possibilidades para uma prática de pesquisa sociológica capaz de apreender a objetividade e a subjetividade inerente ao mundo social, a partir das práticas concretas dos agentes, sempre do ponto de vista relacional.

Essas reflexões colocam em questão a validade típica de objetos da sociologia considerados clássicos, mais relevantes (como classes sociais, poder, Estado, comunidade, religião, ideologia, modo de produção, burocracia, moral, etc), e que estão descolados da prática dos agentes sociais. Por isso, o cientista deve construir seu objeto, relacionálo com a realidade, modificá-lo, acrescentar emendas, enfim é um trabalho de fôlego, às vezes lento, mas absolutamente necessário.

Nesta perspectiva, estudos acerca da microrealidade ou do cotidiano, ganham relevância, pois, se constituem no espaço privilegiado, onde os agentes sociais estruturam suas práticas diariamente. Tais estudos abrem um campo amplo de pesquisas para a sociologia, enriquecendo seu arsenal teórico e metodológico, estimulando a criatividade do pesquisador e o seu compromisso com a cientificidade da sociologia.

As pesquisas de Bourdieu sobre os sistemas simbólicos a nível do campo cultural, científico, artístico e educacional ilustram bem esse esforço pelo avanço de uma sociologia científica, que supera oposições, como: objetivismo-subjetivismo, teoria-empirismo, determinismoespontaneismo.

Sem dúvida, o debate atual sobre a questão subjetividade-objetividade e a relação indivíduosociedade ocorre ainda a partir dos clássicos, porém, está enriquecido pelos elementos colocados pela hermenêutica estruturalista, estruturalismo althusseriano, Escola de Frankfurt, Escola de Budapeste $^{6}$, análises sobre o público e privado de Hannah Arendt, História Nova ${ }^{7}$, entre outros, sem contar o já mencionado P. Bourdieu.

Apreender o conteúdo deste debate é essencial para a compreensão sociológica dos fenômenos culturais, políticos e econômicos da atualidade.

\section{REFERÊNCIAS BIBLIOGRÁFICAS}

ADORNO, T.W. e HORKHEIMER, M. (org.). Temas Básicos da Sociologia. São Paulo: Cultrix, 1978. Cap. 2 e 3.

ALMEIDA, Ana Maria C. A Questão da "alienação" em Karl Marx-exemplo da obra de arte (sugestões para um debate). Semina: Ciências Sociais/Humanas, v.12, n.3, p.119-123, set. 1991.

BOURDIEU, Pierre. O poder simbólico. Lisboa: Difel, 1989.

A Economia das trocas simbólicas. São Paulo:

Perspectiva, 1982. Introdução e p. 154 a 178.

DURKHEIM, E. Lições de Sociologia. A Moral, o Direito e o Estado. São Paulo: T. Queiroz, EDUSP, 1983.

GOLDMAN, L. Ciências Humanas e Filosofia: que é a Sociologia? 2_ Trad. Lupe Cotrim Garaude e José Arthur Giannotti. São Paulo: Difusão Européia do Livro, 1970.

MARX, K. Contribuição para a crítica da economia política. Lisboa: Editorial Estampa, 1973.

A Ideologia Alemã. São Paulo: Grijalbo, 1977.

MICELI, Sérgio. A força do sentido. IN: Bourdieu, P. A economia das trocas simbólicas. (Introdução), São Paulo: Perspectiva, 1982.

WEBER, M. A "objetividade" do conhecimento nas Ciências Sociais. IN: COHN, G. (org.). Weber: Sociologia. 2. ed. São Paulo: Ática, 1982. Coleção Grandes Cientistas Sociais.

\footnotetext{
${ }^{6}$ Ver a respeito da Escola de Frankfurt, BENJAMIN, HOURKHEIMER, ADORNO, HABERMAS. Coleção Os Pensadores, vol. XIVIII, São Paulo: Abril Cultural, 1972 e sobre a Escola de Budapeste COUTINHO, C.N. e Konder, L. Notas sobre Agnes Heller. In: Heller, A. O Cotidiano e a História. Rio de Janeiro: Paz e Terra, 1989.

7 Ver a respeito de Arendt, ARENDT, H. A condição humana. Rio de Janeiro: Forense, 1983 e a respeito da História Nova, LE GOFF, J. A História Nova. São Paulo: Martins Fonte, 1990.
} 